\title{
ПИСЬМА В РЕДАКЦИЮ
}

https://doi.org/10.31063/2073-6517/2021.18-1.10

JEL L22

УДК 336.02

И. О. Блинков

Институт экономики УрО РАН (Екатеринбург, Российская Федерация; e-mail: igor_blinkov@mail.ru)

\section{ПРИНЦИПЫ УПРАВАЕНИЯ КОНКУРЕНТНЫМ ИММУНИТЕТОМ ПРОМЫШАЕННОГО ПРЕАПРИЯТИЯ}

В современных условиях хозяйствования партнерское взаимодействие становится новым вектором решения наукоемких производственных задач на промышленных предприятиях нашей страны. Организация партнерского взаимодействия позволяет оперативно адаптироваться к будущим внешним условиям. Цель статьи состоит в определении методического подхода к формулированию принцииов управления конкурентным иммунитетом промышленного предприятия. Такие принципы раскрывают особенности выстраивания и развития партнерского взаимодействия, акцентируя внимание на возможности повышения его адаптационности за счет объединения комплементарных ресурсов и компетенций юридически независимых, но заинтересованных в сотрудничестве предприятий. Решить задачу партнерского взаимодействия предлагается путем создания координационного совета по управлению межфирменным взаимодействием, состоящего из представителей предприятий-партнеров. Предложенный в статье организационный механизм формирования конкурентного иммунитета производственного предприятия обеспечивает развитие партнерского взаимодействия, повышающего организационную адаптационность промышленного предприятия, и стимулирует его ответную реакцию на постоянные перемены внешней среды.

Ключевые слова: конкуренция, конкурентный иммунитет, организационный механизм, партнерское взаимодействие, промышленное предприятие

Для цитирования: Блинков И. О. Принципы управления конкурентным иммунитетом промышленного предприятия // Журнал экономической теории. 2021. Т. 18. № 1. С. 141-146. https://doi.org/10.31063/2073-6517/2021.18-1.10

\footnotetext{
${ }^{1}$ () Блинков И.О. Текст. 2021
} 
Igor O. Blinkov
Institute of Economics of the Ural Branch of Russian Academy of Sciences (Ekaterinburg, Russian Federation; e-mail: igor_blinkov@mail.ru)

\section{Principles of Competitive Immunity Management of Industrial Enterprises}

In modern business conditions, partnership is becoming a new vector for addressing knowledge-intensive production tasks in Russian industrial enterprises. Partnerships enables enterprises to adjust to changes in the external environment more effectively.

The article aims at describing the methodological approach that would allow to formulate the principles of competitive immunity management of an industrial enterprise. Such principles should be based on establishing partnerships with other enterprises and on expanding the possibilities to increase the enterprise's adaptability by combining its resources with those of partner enterprises. It is proposed to address this task by creating a coordination board comprising representatives of partner enterprises to manage interactions between the companies.

Thus, the proposed mechanism for managing an industrial enterprise's competitive immunity ensures partnership development and enhances this enterprise's adaptability and overall performance.

Keywords: competition, competitive immunity, organizational mechanism, partnership, industrial enterprise

For citation: Blinkov, I. O. (2021). Principles of Competitive Immunity Management of Industrial Enterprises. Zhurnal Economicheskoj Teorii [Russian Journal of Economic Theory], 18(1), 141-146, https://doi.org/10.31063/2073$6517 / 2021.18-1.10$

Мировой опыт развитых стран свидетельствует, что одним из способов самостоятельного решения предприятием адаптационных проблем с минимальными затратами является формирование и развитие партнерского взаимодействия, управление которым может стать новым вектором решения наукоемких производственных задач на отечественных предприятиях в целях повышения эффективности их хозяйственной деятельности и минимизации финансовой роли государства при организации перехода на новый тип инновационно-технологического развития. Организация и управление партнерским взаимодействием промышленного предприятия снизит его уязвимость в условиях новой индустриализации и обеспечит длительное существование на национальных и мировых рынках (Радаев, 2003). П.В. Старцев (2014) обратил внимание на отсутствие единства в понимании терминов «конкурентоспособность предприятия» и «конкурентное преимущество» среди известных исследователейэкономистов. «Однако конкурентоспособность предприятия как научная категория еще мало изучена. Среди основных причин следует выделить постоянную изменчивость условий существования как самого рынка, так и предприятий на нем» (Балашова, Комарницкая, 2016). «Базисом экономической основы конкурентоспособности предприятия является система его конкурентных преимуществ» (Полевая, 2018). Процитированные высказывания являются отправной точкой для разработки методических рекомендаций по формированию организационного механизма управления конкурентным иммунитетом предприятия на базе ключевых характеристик организации партнерского взаимодействия.
Что представляет собой непосредственно конкурентный иммунитет промышленного предприятия? По мнению значительной части ведущих ученых, занимающихся изучением функционирования компаний в условиях жесткой конкуренции (Mescon et. al., 1992; О’Шонесси, 2001), необходимо сказать, в процессе конкуренции присутствует противоречие: деструктивные элементы сочетаются с созидательными. Хотя появляется «возможность минимизации уязвимости от непрогнозируемых угроз действующей экономической реальности за счет синергетического эффекта от делового партнерства и добропорядочных отношений предприятия с властью, наукой, бизнесом и обществом» (Иванова, 2009). Так как речь идет не только о конкурентоспособности, то и было введено в научный оборот группой уральских ученых - А. Татаркиным, С. Важениным, И. Важениной, Д. Копанцевым (2009, 2011, 2012, 2013) - определение конкурентного иммунитета производственного предприятия. Исходя из данного определения, конкурентный иммунитет - способность хозяйствующего субъекта не только успешно вести конкурентную борьбу, но и противостоять потенциальным возникающим угрозам внешних и внутренних потрясений, позволяя восстанавливаться вследствие использования внутренних ресурсов и активов, не востребованных и не задействованных до настоящего времени. Конкурентный иммунитет, таким образом, обеспечивает безопасность существования (финансовую или операционную) на рынке, давая возможность уменьшить уязвимость (с точки зрения экономики предприятия), вызванную ростом масштаба конкуренции, усиливающейся тенденцией 
на расширение и углубление взаимозависимости предприятий на рынках, увеличивающейся нестабильностью экономики. При этом основное внимание уделяется согласованию взаимодействия предприятия с его конкурентами, что значительно сужает поле исследования проблем обеспечения конкурентного сосуществования.

По этой причине, по нашему мнению, конкурентный иммунитет должен быть конкретизирован так: это способность предприятия в первую очередь оперативно адаптироваться к будущим изменениям внешних условий путем организации партнерского взаимодействия с другими хозяйствующими субъектами, а не только защищать и усиливать в течение продолжительного времени свои конкурентные позиции. Поэтому считаем, что, ориентируясь на выживание и устойчивое развитие, в дальнейшем следует расширить перечень партнеров, формирующих конкурентный иммунитет предприятия, учитывая партнерское взаимодействие не только с бизнесом, но и властью и наукой. При этом, так как речь идет о минимизации возможных угроз, следует сделать акцент в большей степени на адаптационные способности и возможности собственного конкурентного иммунитета предприятия к изменению условий внешней среды.

Авторское определение конкурентного иммунитета отличают возможность и способность предприятия в любой момент быстро адаптироваться к будущим изменениям. Это достигается путем оптимизации сотрудничества и делового партнерства с другими существующими на рынке (не только конкурентами) организациями, поиска и достижения компромисса между конкурентами.

Резюмировав все сказанное выше, сделаем вывод, что методологические принципы управления конкурентным иммунитетом промышленного предприятия, под которым понимается защитный механизм конкурентных позиций, работающий на базе объединения взаимодополняющих ресурсов и компетенций юридически самостоятельных предприятий, обеспечивающий их адаптацию к современным условиям хозяйствования, следующие:

- обеспечение достижения общих интересов участников взаимодействия;

- ориентация на долгосрочные отношения при выстраивании партнерского взаимодействия;

- обеспечение равноправности участников в принятии инвестиционных решений;
- распределение выгод исходя из вклада каждого участника в конечный результат;

- синхронное планирование затрат, применяемых технологий, стандартов качества и т. д.;

- создание системы коммуникаций для обмена достоверной информацией между партнерами;

- развитие доверительных отношений между участниками;

- организация социальных сетей для создания основ экономического обмена, в том числе знаниями;

- развитие неформализованных отношений и механизмов разрешения споров.

Показатели адаптационности предприятия интегрируют в себе, как правило, несколько индивидуальных показателей. Их расчет в общем виде представлен формулой:

$$
\mathrm{a}_{i}=\sum_{j=1}^{\mathrm{K}} \mathrm{B}_{j} \mathrm{a}_{i j},
$$

где $\mathrm{a}_{i}$ - показатель адаптационности предприятия к $i$-му внешнему условию; в $_{j}-$ весовой коэффициент внешнего условия $\mathrm{a}_{i}$-показателя; $j=1,2, \ldots, \mathrm{k} ;$ к - количество индивидуальных показателей; $\mathrm{a}_{i j}-$ индивидуальный показатель $\mathrm{a}_{i}$-показателя адаптационности.

В совокупности описанные выше методологические принципы управления конкурентным иммунитетом промышленного предприятия раскрывают управленческие особенности выстраивания и развития партнерского взаимодействия, акцентируя внимание на возможности повышения его адаптационности к условиям новой реальности в производственном бизнесе путем объединения комплементарных ресурсов и компетенций юридически независимых, но заинтересованных в сотрудничестве с ним предприятий.

Еще одним принципом управления конкурентным иммунитетом является принцип обеспечения гибкости производственной деятельности за счет партнерского взаимодействия (Уэлборн, Кастен, 2004). Принцип гибкости производственной деятельности отвечает за обеспечение выпуска новой и качественной продукции. Само понятие качества - это относительный показатель, который можно рассматривать с позиции производителя или с позиции потребителя. Поэтому продукция должна удовлетворять не только требования соответствующих нормативных документов, которые используются в производстве, но требования потребителей (Gerasimov, 2001). Так, одно из положений стандарта ИСО 9001 
Принципы формирования организационного механизма управления конкурентным иммунитетом промышленного предприятия

\begin{tabular}{|l|l|}
\hline $\begin{array}{l}\text { Цель новой индустриализации как базовое условие существова- } \\
\text { ние промышленного предприятия }\end{array}$ & Адаптация через принцип: \\
\hline $\begin{array}{l}\text { Направленность производственной деятельности на снижение } \\
\text { нопортозависимости и повышение экспортной ориентирован- }\end{array}$ & $\begin{array}{l}\text { стабильности производства за счет } \\
\text { партнерства }\end{array}$ \\
\hline $\begin{array}{l}\text { Необходимость диверсификации производства и расширения } \\
\text { сферы деятельности }\end{array}$ & $\begin{array}{l}\text { гибкости производственной деятельно- } \\
\text { сти за счет партнерства }\end{array}$ \\
\hline $\begin{array}{l}\text { Ориентированность на постоянно меняющиеся требования } \\
\text { потребителей }\end{array}$ & $\begin{array}{l}\text { ориентированности на потребителя } \\
\text { за счет партнерства }\end{array}$ \\
\hline $\begin{array}{l}\text { Применение инновационных технологий и выпуск инновацион- } \\
\text { ной продукции }\end{array}$ & $\begin{array}{l}\text { иновационной активности за счет } \\
\text { партнерства }\end{array}$ \\
\hline $\begin{array}{l}\text { Поиск инвестиций } \\
\text { Страхование рисков перехода на современный тип индустри- } \\
\text { альных отношений }\end{array}$ & $\begin{array}{l}\text { иезвестиционной привлекательности } \\
\text { за счет партнерства }\end{array}$ \\
\hline
\end{tabular}

гласит, что организации зависят от своих потребителей, и поэтому они должны представлять их нынешние и перспективные потребности, выполнять их требования и иметь стремление превзойти их ожидания. Поэтому такая цель новой индустриализации, как «ориентированность к постоянно меняющимся требованиям потребителей, будет достижима за счет принципа ориентированности на потребителя на базе партнерского взаимодействия» (Зарецкий, 2012).

Таким образом, получаем, что цели новой индустриализации, выступающие современными условиями хозяйствования, могут быть достигнуты через принципы формирования организационного механизма управления конкурентным иммунитетом промышленного предприятия, обеспечивающие, по сути, адаптацию предприятия к этим условиям (табл.).

Представленные выше принципы составляют методологическую основу организационного механизма управления конкурентным иммунитетом промышленного предприятия.

Очевидным фактом является то, что организация партнерских отношений подразумевает изменение в системах управления партнеров по бизнесу. Решение этой задачи опытным путем часто приводит к преждевременному завершению сотрудничества. Решить эту задачу автор предлагает путем создания координационного совета по управлению межфирменным взаимодействием, состоящего из представителей предприятий-партнеров.

Основными его функциями должны стать разработка и согласование целей, задач и про- ектов межфирменного взаимодействия, организация и контроль за выполнением наукоемких проектов, оценка с группой экспертов конкурентного иммунитета / конкурентного сосуществования промышленного предприятия, выступающего инициатором, а также его бизнес-партнеров, подготовка рекомендаций по совершенствованию адаптационной системы партнерских отношений.

Дополнительными функциями координационного совета должны стать поддержка набранных объемов производства, консолидация конкурентных позиций на захваченных сегментах сбыта продукции, управление имущественным комплексом исходя из соображений целесообразности, значительный рост доходности бизнеса, увеличение эффективности организационной структуры за счет уточнения специализации и реорганизации подразделений, выстраивание оптимальной логистики поставки материалов сырья и сбыта готовой продукции, рациональное управление финансовыми ресурсами и потоками, сконцентрированными на профильном бизнесе и основном производстве, техническое перевооружение производства, основными источниками средств для которого являются собственная прибыль и привлекаемые инвестиции, оптимальная кадровая политика, стремящаяся к расчетно-плановому количеству работающих, с периодическим осуществлением внутреннего перераспределения рабочей силы, улучшение экологии, санитарии и условий труда на современном уровне развития очистительных технологий и сооружений. 
Таким образом, координационный совет фактически выполняет функции управления совместным проектом, в том числе по созданию наукоемкой продукции. При прекращении функционирования системы партнерских отношений данный совет распускается или трансформируется в другой управляющий аппарат координации сотрудничества.
В заключение можно отметить, что авторский организационный механизм формирующегося конкурентного иммунитета производственного предприятия обеспечивает развитие партнерского взаимодействия, повышающего организационную адаптационность промышленного предприятия, и стимулирует его ответную реакцию на трансформацию условий внешней среды.

\section{Список источников}

Балашова Р.И., Комарницкая Е.В. Конкурентоспособность предприятия как экономическая категория // Экономические исследования и разработки. 2016. № 3. С. 75-86.

Блинков И.О. Стратегия формирования конкурентного иммунитета промышленных предприятий в регионе // Сборник научных статей XIV Международной научно-практической конференции молодых ученых «Развитие территориальных социально-экономических систем: вопросы теории и практики». Екатеринбург: Институт экономики УрО РАН, 2016. С. 168-171.

Блинков И. О., Блинков О.Г., Сериков Д. Ю. Оценка результативности внедрения инноваций как фактора конкурентного иммунитета промышленного предприятия // Оборудование и технологии для нефтегазового комплекса. 2019. № 4(112). С.48-51.

Блинков И.О., Крылатков П. П. Формирование конкурентного иммунитета промышленных предприятий в условиях новой индустриализации // Известия Уральского государственного экономического университета. 2016. № 2 (64). С. 68-77.

Важенин С. Г., Важенина И.С. Горизонты территориальной конкуренции в современном экономическом пространстве // Общество и экономика. 2011. № 3. С. 67-85.

Важенин С. Г., Важенина И. С. Феномен конкурентного иммунитета территории // Общество и экономика. 2009. № 11-12. C. 139-156.

Важенин С. Г., Важенина И. С. Концептуальные основы конкурентного сосуществования территорий // Журнал экономической теории. 2012. № 3. С. 96-105.

Зареикий А.Д. Региональная политика по формированию конкурентного иммунитета монотерриторий // Региональная экономика. - 2012. № 4. URL: http:// uecs.ru/uecs40-402012/item/1331-2012-05-05-08-25-57.

Иванова Т. В. Подходы к оценке конкурентоспособности промышленных предприятий при формировании интегрированной бизнес-группы // Вестник Омского университета. Серия «Экономика». 2009. № 4. С. 107-113.

Копанщев Д. В., Важенин С. Г. Уязвимость и жизнестойкость компаний в современном экономическом пространстве // Экономика региона. 2011. № 3. С. 224-228.

О’Шонесси Дж. Конкурентный маркетинг. Стратегический подход. - СПб.: Питер, 2001. С. 24-29.

Полевая Е. В. Повышение конкурентоспособности предприятия // Инновационная экономика: материалы V Междунар. науч. конф. (г. Казань, май 2018 г.). Казань: Молодой ученый, 2018. С. 7-13.

Радаев В. В. Социология рынков. К формированию нового направления. М.: ГУ ВШЭ, 2003. 328 с.

Стариев П. В. Анализ подходов к сущности понятий «конкурентоспособность предприятия» и «конкурентное преимущество» // Российское предпринимательство. 2014. № 16(262). С. 4-15.

Татаркин А. И. Конкурентное позиционирование регионов и территорий в пространственном развитии России // Вестник ОГУ. 2013. № 8 (157). С. 148-158.

Уэлборн Р., Кастен В. Деловые партнёрства, как преуспеть в совместном бизнесе: пер. с англ. М.: ООО «Вершина», 2004. 336 c.

Meskon M. H., Albert M., Hedouri F. Basics of management. M.: Delo, 1992.

Gerasimov A. E. Problems of Innovative Activity Efficiency Improvement // Innovatsii. 2001. Vol. 12(9). P. 58-61.

\section{References}

Balashova, R. I., \& Komarnickaya, E. V. (2016). Konkurentosposobnost' predpriyatiya kak ekonomicheskaya kategoriya [The competitiveness of the enterprise as an economic category]. Ekonomicheskie issledovaniya $i$ razrabotki [Economic development research journal], 3, 75-86. (In Russ.)

Blinkov, I. O. (2016). Strategiya formirovaniya konkurentnogo immuniteta promyshlennykh predpriyatiy v regione [Strategy for the formation of competitive immunity of industrial enterprises in the region]. Sbornik nauchnykh statey XIV Mezhdunarodnoy nauchno-prakticheskoy konferentsii molodykh uchenykh "Razvitie territorial'nykh sotsial'no-ekonomicheskikh sistem: voprosy teorii i praktiki" [Collection of scientific articles of the XIV International scientific-practical conference of young scientists "Development of territorial socio-economic systems: theory and practice"]. Ekaterinburg: Institut ekonomiki UrO RAN, 168-171. (In Russ.)

Blinkov, I. O., Blinkov, O. G., \& Serikov, D. Yu. (2019). Otsenka rezul'tativnosti vnedreniya innovatsiy kak faktora konkurentnogo immuniteta promyshlennogo predpriyatiya [Evaluation of innovations implementation effectiveness as 
a factor of competitive immunity of an industrial enterprise]. Oborudovanie i tekhnologii dlya neftegazovogo kompleksa [Equipment and technologies for oil and gas complex], 4(112), 48-51. (In Russ.)

Blinkov, I. O., \& Krylatkov, P. P. (2016). Formirovanie konkurentnogo immuniteta promyshlennykh predpriyatiy v usloviyakh novoy industrializatsii [Formation of Competitive Immunity of Industrial Enterprises Under the New Industrialization]. Izvestiya Ural'skogo gosudarstvennogo ekonomicheskogo universiteta [Journal of new economy], 2(64), 68-77. (In Russ.)

Vazhenin, S. G., \& Vazhenina, I. S. (2011). Gorizonty territorial'noy konkurentsii v sovremennom ekonomicheskom prostranstve [Competition in the modern skyline of territorial economic area]. Obshchestvo i ekonomika [Society and Economy], 3, 67-85. (In Russ.)

Vazhenin, S. G., \& Vazhenina, I. S. (2009). Fenomen konkurentnogo immuniteta territorii [Essence of competitive immunity of territory]. Obshchestvo i ekonomika [Society and Economy], 11-12, 139-156. (In Russ.)

Vazhenin, S. G., \& Vazhenina, I. S. (2012). Kontseptual'nye osnovy konkurentnogo sosushchestvovaniya territoriy [Conceptual foundations of competitive coexistence of territories]. Zhurnal ekonomicheskoj teorii [Russian Journal of Economic Theory], 3, 96-105. (In Russ.)

Zaretskiy, A. D. (2012). Regional'naya politika po formirovaniyu konkurentnogo immuniteta monoterritoriy [Regional policy on the formation of competitive mono-territories immunity]. Regionalnaya ekonomika [Regional Economics], 4. Retrieved from: http:// uecs.ru/uecs40-402012/item/1331-2012-05-05-08-25-57 (In Russ.)

Ivanova, T. V. (2009). Podkhody k otsenke konkurentosposobnosti promyshlennykh predpriyatiy pri formirovanii integrirovannoy biznes-gruppy [Enterprise competitiveness and forming integrated business-group]. Vestnik Omskogo universiteta. Seriya "Ekonomika» [Herald of Omsk University. Series Economics], 4, 107-113. (In Russ.)

Kopantsev, D. V., \& Vazhenin, S. G. (2011). Uyazvimost' i zhiznestoykost' kompaniy v sovremennom ekonomicheskom prostranstve [The vulnerability and resilience of the company in modern economic space]. Ekonomika regiona [Economy of region], 3, 224-228. (In Russ.)

O'Shaughnessy, J. (2001). Konkurentnyy marketing. Strategicheskiy podkhod [Competitive marketing: a strategic approach]. SPb: Piter, 24-29. (In Russ.)

Polevaya, E. V. (2018). Povyshenie konkurentosposobnosti predpriyatiya [Increasing the competitiveness of the enterprise]. Innovatsionnaya ekonomika: materialy V Mezhdunar. nauch. konf. (g. Kazan', may 2018 g.). [Innovative economy: materials of the V International. (Kazan, may, 2018]. Kazan: Molodoy uchenyy, 7-13. (In Russ.)

Radaev, V. V. (2003). Sotsiologiya rynkov. K formirovaniyu novogo napravleniya [Sociology of markets. Towards the formation of a new direction]. Moscow: GU VShE, 328. (In Russ.)

Startsev, P. V. (2014). Analiz podkhodov k sushchnosti ponyatiy «konkurentosposobnost' predpriyatiya» i «konkurentnoe preimushchestvo» [Analysis of approaches to the essence of "competitive capacity of an enterprise" and "competitive advantage" concepts]. Rossiyskoe predprinimatel'stvo [Russian journal of entrepreneurship], 16(262), 4-15. (In Russ.)

Tatarkin, A. I. (2013). Konkurentnoe pozitsionirovanie regionov i territoriy v prostranstvennom razvitii Rossii [Competitive regional and territories positioning in the spatial development of the Russian Federation]. Vestnik OGU [Vestnik Orenburg State University], 8(157), 148-158. (In Russ.)

Welborn, R., \& Kasten, V. (2004). Delovye partnerstva, kak preuspet'v sovmestnom biznese [Business partnerships. How to succeed in contemporary business]. Translated. Moscow: OOO «Vershina», 336. (In Russ.)

Meskon, M. H., Albert, M., \& Hedouri, F. (1992). Basic of management. Moscow: Delo.

Gerasimov, A. E. (2001). Problems of Innovative Activity Efficiency Improvement. [Innovatsii], 12(9), 58-61.

\section{Информация об авторе}

Блинков Игорь Олегович - соискатель, Институт экономики УрО РАН (Екатеринбург, Российская Федерация; e-mail: igor_blinkov@mail.ru).

\section{Author}

Igor O. Blinkov - Candidate, Institute of Economics of the Ural Branch of Russian Academy of Sciences (Ekaterinburg, Russian Federation; e-mail: igor_blinkov@mail.ru). 